\title{
A holistic FMEA approach by fuzzy-based Bayesian network and best-worst method
}

\author{
Melih Yucesan $^{1}$ (D) $\cdot$ Muhammet Gul ${ }^{2}$ Erkan Celik ${ }^{3}$
}

Received: 14 September 2020 / Accepted: 18 January 2021 / Published online: 18 February 2021

(c) The Author(s) 2021

\begin{abstract}
Failure mode and effect analysis (FMEA) is a risk analysis tool widely used in the manufacturing industry. However, traditional FMEA has limitations such as the inability to deal with uncertain failure data including subjective evaluations of experts, the absence of weight values of risk parameters, and not considering the conditionality between failure events. In this paper, we propose a holistic FMEA to overcome these limitations. The proposed approach uses the fuzzy best-worst (FBWM) method in weighting three risk parameters of FMEA, which are severity $(S)$, occurrence $(O)$, and detection $(D)$, and to find the preference values of the failure modes according to parameters $S$ and $D$. On the other side, it uses the fuzzy Bayesian network (FBN) to determine occurrence probabilities of the failure modes. Experts use a procedure using linguistic variables whose corresponding values are expressed in trapezoidal fuzzy numbers, and determine the preference values of the failure modes according to parameter $O$ in the constructed BN. Thus, the FBN including expert judgments and fuzzy set theory addresses uncertainty in failure data and includes a robust probabilistic risk analysis logic to capture the dependence between failure events. As a demonstration of the approach, a case study was conducted in an industrial kitchen equipment manufacturing facility. The results of the approach have also been compared with existed methods demonstrating its robustness.
\end{abstract}

Keywords Failure mode and effect analysis · Bayesian network · Trapezoidal fuzzy set · Best-worst method · Industrial kitchen equipment manufacturing

\section{Introduction}

Failure is a state or condition of not meeting a desired or intended objective. For production environments, this concept is defined as the component that causes damage to engineering equipment, manufactured products or plant infrastructure, affecting operation, production and performance as well as the company's brand and reputation [21]. Planning of failure analysis within the context of risk and reliability is a strategy that contributes to minimizing the total cost, increasing the number of production, and producing higher

Melih Yucesan

melihyucesan@munzur.edu.tr

1 Department of Mechanical Engineering, Munzur University, 62000 Tunceli, Turkey

2 Department of Emergency Aid and Disaster Management, Munzur University, 62000 Tunceli, Turkey

3 Department of Transportation and Logistics, Istanbul University, 34322 Avc1lar, Istanbul, Turkey quality products [28]. In addition, failure analysis is very effective in determining the price policies of companies [6].

Faulty product is one of the main problems faced by companies. This problem does not only result in financial loss but also causes loss of prestige (Boral et al. 2020). To continue the activities of the companies in a healthy and to make profit in today's overwhelming competitive environment, they must increase their production quality and decrease the number of faulty products [39].

The demand for commercial cooking equipment is increasing day by day, especially due to the developments in the hotel industry. Commercial cooking equipment has a wide range of products for the preparation of large-scale dishes. The development of new cooking techniques and the differentiation of existing cooking techniques by reinterpreting increase the importance of cooking equipment day by day. In addition, this equipment is used in the training of chefs. As the quality of these equipment has a direct impact on human health, production requires special care and precision. Due to the factors mentioned above, commercial cooking equipment demands in the global market 
are expected to increase day by day and reach new heights (URL-1). The global commercial kitchen equipment market size is expected to grow by $6.7 \%$ annually in $2020-2027$ (URL-2). Although the production process of industrial kitchen equipment is relatively simple, inevitably, the failure analysis and control attempts to be made for this sector will contribute economically to the enterprises since high volume production is realized.

To evaluate failures and comment regarding their possible effects, some systematic techniques are required such as the Bow-tie method (BT), event-tree analysis (ETA), fault tree analysis (FTA) and failure mode and effects analysis (FMEA) [7]. FMEA is one of the methods used to specify and sort failure modes (FMs). FMEA was applied for the first time in 1960 to solve problems in the space and automobile industry [8]. Thanks to the FMEA analysis, the effects of the FMs on the system performance can be determined so that necessary measures can be taken $[9,35]$. The risk priority number (RPN) is used as the prioritization index in FMEA analysis. The three factors used in the calculation of RPN as product failure severity, probability of failure occurrence and the probability of failure detection. RPN is calculated by multiplying $\mathrm{S}, \mathrm{O}$, and $\mathrm{D}$ parameters [47]. It is integrated with many multi-criteria decision-making (MCDM) methods, data analytics methods, and sophisticated methods. Since its traditional version has limitations such as the inability to deal with uncertain failure data including subjective expert judgments, the absence of weight values for risk parameters, and not taking into account the conditionality between failure events, it has extended by incorporating BWM, BN and fuzzy set theory [11, 64].

Fuzzy best-worst method (FBWM) has many drawbacks compared to pairwise comparison-based MCDM methods like fuzzy analytical hierarchy process (FAHP). This method determines the importance weights of the criteria by providing fewer pairwise comparisons and more consistent comparison matrices. The best criterion has the most vital role in decision making, while the worst criterion has the opposite role. Moreover, this method not only obtains the weights independently, but can also be integrated with other MCDM methods. In this study, we use this method under an FMEA study.

On the other hand, the Bayesian Networks (BNs) are visual tools based on probability theory. The use of this method in failure analysis is possible by showing the relationships of failure events and the conditional probability structure between them. It is frequently used to explain uncertainty. In this study, the fuzzy version of this method "fuzzy Bayesian Network-FBN" is used in the context of an FMEA study. The evaluator role of experts in failure analysis problems requires the use of fuzzy logic theory in the face of various uncertainties. Subjectivity and uncertainty in the judgments of the evaluators about the FMs is an important and difficult problem that also occurs in the solution of the problem addressed in this study. The fuzzy set theory presented by Zadeh [61] has been previously applied to the solution of many decision problems. This theory has been developed over time and transformed into different versions and these versions have been effectively applied to many decision problems. Triangular and trapezoidal fuzzy sets are among these extensions which are widely used by scholars.

In this paper, we propose a holistic FMEA study including FBWM and FBN. The FBWM is used in the holistic approach:

(1) to determine weights for three risk parameters of FMEA ( $S, O$ and $D)$,

(2) to find the preference values of the FMs with respect to two parameters (S and D).

On the other side, FBN is used to determine the occurrence probabilities (the remaining parameter of FMEA and indicated as "O") of FMs in BN structure. Experts use a procedure adapted from Aliabadi et al. [3] using linguistic variables whose corresponding values are expressed in trapezoidal fuzzy numbers, and determine the occurrence probability of each FM in the constructed BN. As a case study application of the approach, a risk assessment was performed in an industrial kitchen equipment manufacturing facility. The results of the approach have also been compared with an FMEA-based FBWM method without including a $\mathrm{BN}$ to provide its robustness.

In the lights of abovementioned short comments on the aims of the study, the contributions may be shortened as follows:

(1) FBWM is utilized to eliminate a drawback of FMEA which is related to the absence of weight values of risk parameters. At the same time, evaluations of each FM are performed with respect to $\mathrm{S}$ and $\mathrm{D}$ parameters by the aid of FBWM computation logic to obtain preference values.

(2) $\mathrm{A} \mathrm{BN}$ is designed to demonstrate conditionality between main FMs and auxiliary FMs for the studied industrial kitchen equipment manufacturing facility.

(3) Using an adapted FBN procedure of Aliabadi et al. [3], final occurrence probabilities (preference values of FMs with respect to parameter "O") of each FM are computed.

(4) Obtained preference values of FMs with respect to FMEA risk parameters from both FBWM (for parameters $\mathrm{S}$ and $\mathrm{D}$ ) and FBN (for parameter $\mathrm{O}$ ) are then merged to determine final RPN of each FM. To the best of authors' knowledge, this is the initial attempt that merges FBN and FBW as performed in this study. 


\section{Literature review}

In the literature, many scholars have dealt with FMEA extensions (with BN and BWM) and applied it to risk analysis problems. For a detailed view, Table 1 presents a comprehensive review of previous FMEA studies integrating FMEA, (F)BWM and/or (F)BN. In addition, in Table 1, novelty of each study is explained with details. BWM (either in fuzzy form) and BWM (either in fuzzy form) are used together with FMEA concept in an equal number of studies (see Table 1). Moreover, some studies $[12,14,17,18,20,24,34,36,42,43,46,54,56,57,62]$ use an auxiliary concept such as fuzzy MOORA, MULTIMOORA, Z-MOORA, Markov chain, GRA, VIKOR, TOPSIS, multi-objective mathematical programming, WASPAS, COPRAS, Bow-tie analysis, FTA and casebased reasoning. Lee [27] integrated FMEA and BN in the modeling of an inkjet printer. Yang et al. [58] applied fuzzy rule-based Bayesian reasoning with FMEA in the maritime industry. Yang et al. [57] demonstrated a Bayesian-based FTA and FMEA methods in software industry failure assessment. García and Gılabert (2011) created a $\mathrm{BN}$ in FMEA analysis of marine diesel engine systems. Ma et al. [36] designed an FMEA and FTA integrated model for BN. Zarei et al. [62] performed a risk assessment model for natural gas stations by FMEA, Bow-Tie and BN. Yang et al. [56] used case-based reasoning and FMEA together and applied for software failure assessment. Rastayesh et al. [48] performed an FMEA-BN integrated model for risk analysis in telecommunication. Nie et al. [43] proposed a novel FMEA method with FBWM, GRA, TOPSIS, and performed an implementation in an aero-engine turbine. Huang et al. [23] present a systematic review of FMEA during the years between 1998 and 2018. They analyzed 236 papers on FMEA. Interested readers and researchers can look at this useful review paper.

\section{Methodology}

\section{Failure mode and effect analysis (FMEA)}

FMEA is an old risk assessment method implemented in different application areas from manufacturing to service. It originated in the field of aerospace as a design tool by NASA in 1960s. Since then, various improvements are provided on the base version. Various sector-based types are developed such as manufacturing, service of design FMEA [52]. It contains three factors of S, O, and D. A RPN by multiplying these parameters is obtained. Each parameter takes values between 1 and 10 ( 1 refers to the lowest and 10 refers to the highest) [9]. Failures result in high RPN are critical and are ranked of first priority. Failures with low RPN are vice versa [45]. At the final stage, control measure suggestion is considered. Although this traditional FMEA has a strong ability in system safety assessment, there exist lots of drawbacks that are stated in the literature $[4,21],[9,30,33,44,45]$. Some of those are summarized in Table 2.

More shortcoming can be found in Liu et al. [33], which is a comprehensive review of previous FMEA literature.

\section{Fuzzy best-worst method (FBWM)}

The best-worst method (BWM) is initially proposed by Rezaei [49]. It is used to obtain the importance weights of criteria in a multi-criteria decision problem. The method is based on evaluations considering the best and the worst of criterion among others [50]. Then, the model is solved as a max-min optimization problem. It is applied to various fields from manufacturing to service [37]. After its initial development and applying to various areas, it has also been extended methodologically by fuzzy sets [41]. Guo and Zhang [22] developed triangular FBWM and applied it in the logistics industry. In the following, we provide a summarization of the steps of FBWM in Fig. 1.

In determining the fuzzy weights via the FBWM method, an optimization model is required. The best-to-others $\left(\tilde{w}_{B} / \tilde{w}_{j}\right)$ and the worst-to-others $\left(\tilde{w}_{j} / \tilde{w}_{W}\right)$ should have $\tilde{w}_{B} / \tilde{w}_{j}=\tilde{a}_{B j}$ and $\tilde{w}_{j} / \tilde{w}_{W}=\tilde{a}_{j W} \cdot\left|\tilde{w}_{B} / \tilde{w}_{j}-\tilde{a}_{B j}\right| \quad$ and $\left|\tilde{w}_{j} / \tilde{w}_{W}-\tilde{a}_{j W}\right|$ for each criterion are minimized. The demonstration of any criterion matrix in TFNs is as $\tilde{w}_{j}=\left(l_{j}^{w}, m_{j}^{w}, u_{j}^{w}\right)$. The model to obtain fuzzy weights is constructed as follows:

$$
\begin{aligned}
& \min \max _{j}\left\{\left|\tilde{w}_{B} / \tilde{w}_{j}-\tilde{a}_{B j}\right|,\left|\tilde{w}_{j} / \tilde{w}_{W}-\tilde{a}_{j W}\right|\right\} \\
& \text { s.t. }\left\{\begin{array}{l}
\sum_{j=1}^{n} R\left(w_{j}\right)=1 \\
l_{j}^{w} \leq m_{j}^{w} \leq u_{j}^{w} \\
l_{j}^{w} \geq 0 \\
j=1,2, \ldots, n
\end{array}\right.
\end{aligned}
$$

H e r e $\quad \tilde{w}_{B}=\left(l_{B}^{w}, m_{B}^{w}, u_{B}^{w}\right), \tilde{w}_{j}=\left(l_{j}^{w}, m_{j}^{w}, u_{j}^{w}\right)$ $, \tilde{w}_{W}=\left(l_{W}^{w}, m_{W}^{w}, u_{W}^{w}\right), \tilde{a}_{B j}=\left(l_{B j}, m_{B j}, u_{B j}\right) \tilde{a}_{j W}=\left(l_{j W}, m_{j W}, u_{j W}\right)$. The current version of the model is a constrained optimization problem. To satisfy the conditions given below the objective function statement in Eq. (1), a solution where the maximum absolute differences of $\left|\tilde{w}_{B} / \tilde{w}_{j}-\tilde{a}_{B j}\right|$ and $\left|\tilde{w}_{j} / \tilde{w}_{W}-\tilde{a}_{j W}\right|$ for all $j$ should be minimized. This state of the problem is a min-max

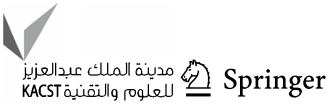


Table 1 Analysis of previous studies integrating FMEA, (F)BWM and/or (F)BN

\begin{tabular}{|c|c|c|c|c|c|c|}
\hline \multirow[t]{2}{*}{ Study } & \multicolumn{4}{|c|}{ Approach } & \multirow[t]{2}{*}{ Other concept } & \multirow[t]{2}{*}{ Novelty } \\
\hline & FMEA & (F)BWM & $(\mathrm{F}) \mathrm{BN}$ & Fuzzy extension & & \\
\hline Dorosti et al. (2020) & $\sqrt{ }$ & $\sqrt{ }$ & & $\begin{array}{l}\text { Triangular fuzzy number } \\
\text { (TFN) }\end{array}$ & Fuzzy-MOORA & $\begin{array}{l}\text { *Criterion weights deter- } \\
\text { mined by FBWM } \\
\text { *FMs ranked by fuzzy } \\
\text { MOORA }\end{array}$ \\
\hline Gul et al. (2020) & $\sqrt{ }$ & $\sqrt{ }$ & $\sqrt{ }$ & TFN & - & $\begin{array}{l}\text { *FMEA parameters deter- } \\
\text { mined hierarchically } \\
\text { *Combined with the fuzzy } \\
\text { rule-based and BN } \\
\text { *An RPN calculation algo- } \\
\text { rithm used }\end{array}$ \\
\hline Dezan et al. (2020) & $\sqrt{ }$ & & $\sqrt{ }$ & - & Markov Process & $\begin{array}{l}\text { *BN used to develop failure } \\
\text { detection modules } \\
\text { *FMEA carried out for } \\
\text { autonomous vehicles } \\
\text { *BN merged with Markov } \\
\text { Decision Process }\end{array}$ \\
\hline Kirchhof et al. (2020) & $\sqrt{ }$ & & $\sqrt{ }$ & - & - & $\begin{array}{l}\text { *Risk analysis performed in } \\
\text { the production of lithium } \\
\text { ion battery } \\
\text { *A new method combin- } \\
\text { ing the expert knowledge } \\
\text { acquisition with FMEA } \\
\text { *A special algorithm } \\
\text { introduced to detect } \\
\text { inconsistencies in experts' } \\
\text { evaluations }\end{array}$ \\
\hline Cheng et al. (2020) & $\sqrt{ }$ & $\sqrt{ }$ & & $\begin{array}{l}\text { Trapezoidal neutrosophic } \\
\text { numbers }\end{array}$ & MULTIMOORA & $\begin{array}{l}\text { *Subjective and objective } \\
\text { weights calculated by } \\
\text { BWM } \\
\text { *MULTIMOORA used for } \\
\text { RPN calculation in surgical } \\
\text { procedures }\end{array}$ \\
\hline Wan et al. (2019) & $\sqrt{ }$ & & $\sqrt{ }$ & TFN & - & $\begin{array}{l}* \text { Evaluating the risks in the } \\
\text { maritime supply chain } \\
* \text { Presenting an integrated } \\
\text { methodology using FMEA } \\
\text { and BN } \\
\text { *Proposed a fuzzy belief } \\
\text { rule-based BN approach }\end{array}$ \\
\hline Khalilzadeh et al. (2020) & $\sqrt{ }$ & $\sqrt{ }$ & & TFN & $\begin{array}{l}\text { GRA, VIKOR, multi- } \\
\text { objective mathematical } \\
\text { programming }\end{array}$ & $\begin{array}{l}\text { *FMEA integrated with } \\
\text { GRA and VIKOR } \\
\text { *Performance indicators } \\
\text { for each risk weighted by } \\
\text { BWM } \\
\text { *Strategies determined by a } \\
\text { multi-objective mathemati- } \\
\text { cal program }\end{array}$ \\
\hline Kolagar et al. (2020) & $\sqrt{ }$ & $\sqrt{ }$ & & TFN & - & $\begin{array}{l}\text { *Surgical cancellation fac- } \\
\text { tors weighted by FBWM } \\
\text { *Computed a fuzzy RPN }\end{array}$ \\
\hline Momen et al. (2019) & $\sqrt{ }$ & $\sqrt{ }$ & & TFN & - & $\begin{array}{l}\text { *FMs in hemodialysis } \\
\text { weighted by FBWM }\end{array}$ \\
\hline Rastayesh et al. (2019) & $\sqrt{ }$ & $\sqrt{ }$ & & - & - & $\begin{array}{l}* \text { The BN constructed based } \\
\text { on the FMEA criteria }\end{array}$ \\
\hline Nie et al. (2019) & $\sqrt{ }$ & & $\sqrt{ }$ & - & GRA, TOPSIS & $\begin{array}{l}\text { *BN used for identified FMs } \\
\text { *GRA and TOPSIS applied } \\
\text { to prioritize FMs }\end{array}$ \\
\hline
\end{tabular}


Table 1 (continued)

\begin{tabular}{llll}
\hline Study & \multicolumn{2}{l}{ Approach } & Other concept Novelty \\
& &
\end{tabular}

Ghoushchi et al. (2019)

TFN

Z-MOORA

*A new FMEA approach

introduced

*The weighting of the risks performed by FBWM

*Failures prioritized by a Z-MOORA

Chang et al. (2019)

$\sqrt{ } \quad \sqrt{ }$

TFN

TOPSIS, WASPAS

*FMEA-based multiattribute decision-making implemented

*FMs weighted by FBWM

*FMs ranked by TOPSIS

*A WASPAS-based methodology proposed for RPN calculation

Tian et al. (2018)

$$
\sqrt{ } \quad \sqrt{ }
$$

TFN

VIKOR

Peko et al. (2018)

$$
\sqrt{ } \quad \sqrt{ }
$$

$-$

TOPSIS

Liu et al. (2018)

Lo and Liou (2018)

Nie et al. (2018)

Yang et al. (2018)

Zarei et al. (2017)

Ma et al. (2014)

$\sqrt{ } \quad \sqrt{ } \quad$ Fuzzy number

$\sqrt{ }$

$\sqrt{ }-$

Case-based reasoning

Bow-tie analysis

*Risk factors weighted by FBWM

*The rank of risks determined by fuzzy VIKOR

* Cost criterion attached to FMEA parameters

*The parameters calculated by BWM

*FMs ranked by TOPSIS

* BWM under two-dimensional uncertain linguistic are used to weight risk factors

*The cost variable added to the RPN calculation

*The general RPN calculation modified

*BWM and GRA integration used

*FMEA carried out for electronics industry

*BWM used to determine the weights

* COPRAS is extended for ranking FMs

*CBR and BN-based diagnosis combined to overcome traditional FMEA

*A proposed model used in the deep-level Bayesian dynamic and uncertainty diagnostics network

*A dynamic risk analysis performed for gas station safety assessment

*Basic events and minimal cut sets configured by the probability update

FTA, BN and FMEA integration model proposed for system reliability and safety analysis 
Table 1 (continued)

\begin{tabular}{|c|c|c|c|c|c|}
\hline \multirow[t]{2}{*}{ Study } & \multicolumn{3}{|l|}{ Approach } & \multirow[t]{2}{*}{ Other concept } & \multirow[t]{2}{*}{ Novelty } \\
\hline & FMEA (F)BWM & (F)BN & Fuzzy extension & & \\
\hline García and G1labert (2011) & $\sqrt{ }$ & $\sqrt{ }$ & - & - & $\begin{array}{l}* \text { The failure analysis imple- } \\
\text { mented for marine diesel } \\
\text { engine } \\
* \text { The evaluations to be used } \\
\text { obtained with the help of } \\
\text { sensors }\end{array}$ \\
\hline Lian et al. (2010) & $\sqrt{ }$ & $\sqrt{ }$ & - & - & $\begin{array}{l}\text { *FMEA and cause failure } \\
\text { effect type Bayesian net- } \\
\text { work topology created }\end{array}$ \\
\hline Yang et al. (2008) & $\sqrt{ }$ & $\sqrt{ }$ & - & - & $\begin{array}{l}\text { * Subjective belief degrees } \\
\text { assigned by fuzzy rule base } \\
\text { * Maritime risk analysis car- } \\
\text { ried out }\end{array}$ \\
\hline Yang et al. (2009) & $\sqrt{ }$ & $\sqrt{ }$ & - & FTA & $\begin{array}{l}\text { *A case study carried out for } \\
\text { the software industry } \\
\text { *A fault diagnosis model } \\
\text { proposed using a combina- } \\
\text { tion of FMEA, FTA and } \\
\text { BN }\end{array}$ \\
\hline Calori (2007) & $\sqrt{ }$ & $\sqrt{ }$ & - & - & $\begin{array}{l}\text { *The system separated into } \\
\text { components by Jacobson } \\
\text { analysis } \\
\text { *FMEA performed } \\
\text { *BN established by FMEA } \\
\text { parameters }\end{array}$ \\
\hline Lee (2001) & $\sqrt{ }$ & $\sqrt{ }$ & - & - & $\begin{array}{l}\text { *Integrating BN and FMEA } \\
\text { *Directed acyclic graph } \\
\text { models construction }\end{array}$ \\
\hline
\end{tabular}

Table 2 Drawbacks of the FMEA method

\begin{tabular}{|c|c|c|}
\hline \# & Drawback & Useful reference(s) \\
\hline 1 & Not mentioning weights of $\mathrm{S}, \mathrm{O}$ and $\mathrm{D}$ & $\begin{array}{l}\text { Park et al. (2018); Liu et al. (2013); Huang et al. (2017); Başhan et al. } \\
\text { (2020) }\end{array}$ \\
\hline 2 & The case that different $S, O$ and $D$ values can have the same RPN & $\begin{array}{l}\text { Huang et al. (2017); Catelani et al. (2018); Du et al. (2016); Safari et al. } \\
\text { (2016); Gul et al. (2020) }\end{array}$ \\
\hline 3 & Limitation in the number of parameters that classic FMEA has & Du et al. (2016); Lo et al. (2019); Seiti et al. (2020) \\
\hline 4 & $\begin{array}{l}\text { Difficulty in the precise examination of risk parameters due to } \\
\text { their subjective evaluation on a scale of } 1-10\end{array}$ & $\begin{array}{l}\text { Ozdemir et al. (2017); Zhao et al. (2017); Lo et al. (2019); Kutlu and } \\
\text { Ekmekçioğlu (2012); Zhang et al. (2020) }\end{array}$ \\
\hline
\end{tabular}




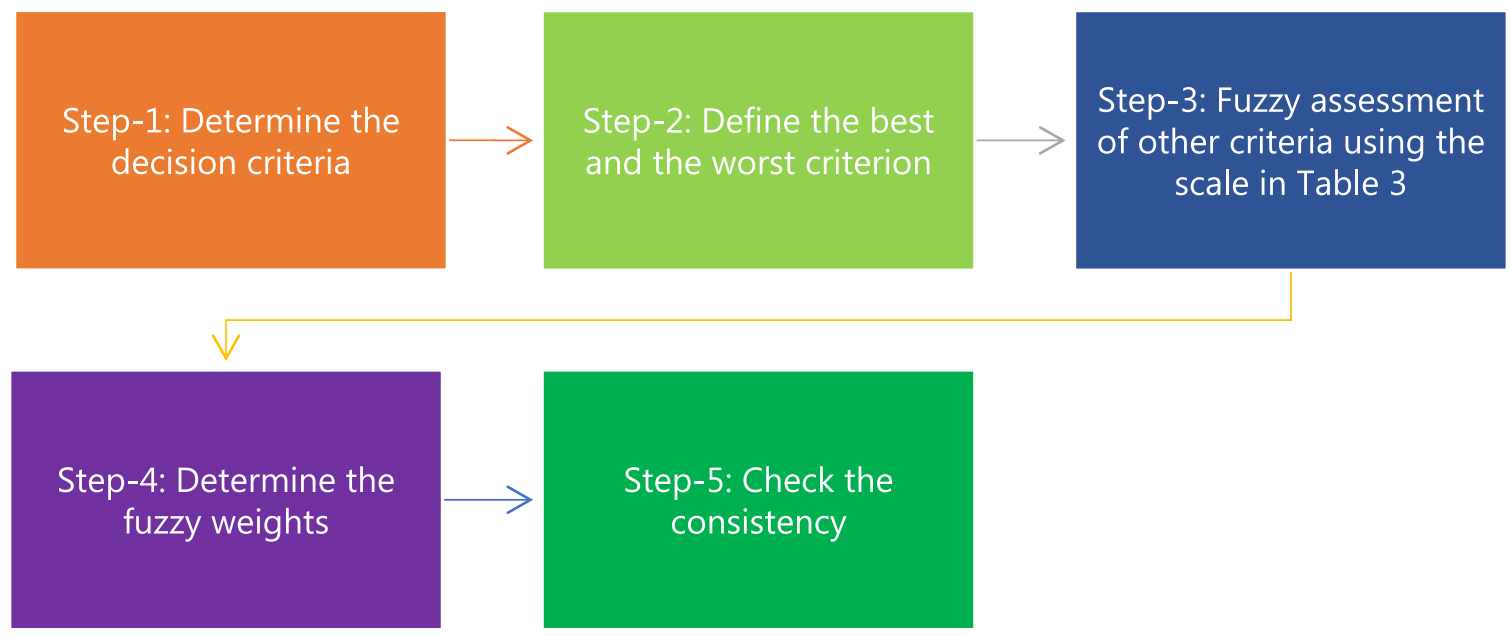

Fig. 1 The flowchart of the FBWM method

problem. Then, Eq. (1) is remodeled as a nonlinearly constrained optimization problem as follows:

$\min \xi$

s.t. $\left\{\begin{array}{l}\left|\tilde{w}_{B} / \tilde{w}_{j}-\tilde{a}_{B j}\right| \leq \xi \\ \left|\tilde{w}_{j} / \tilde{w}_{W}-\tilde{a}_{j W}\right| \leq \xi \\ \sum_{j=1}^{n} R\left(\tilde{w}_{j}\right)=1 \\ l_{j}^{w} \leq m_{j}^{w} \leq u_{j}^{w} \\ l_{j}^{w} \geq 0 \\ j=1,2, \ldots, n\end{array}\right.$

where $\xi=\left(l^{\xi}, m^{\xi}, u^{\xi}\right)$, considering $l^{\xi} \leq m^{\xi} \leq u^{\xi}$. $\zeta^{*}=\left(k^{*}, k^{*}, k^{*}\right), k^{*} \leq l^{\zeta}$, Eq. (2) is transformed as: $\min \xi^{*}$

$$
\text { s.t. }\left\{\begin{array}{l}
\left|\left(l_{B}^{W}, m_{B}^{W}, u_{B}^{W}\right) /\left(l_{j}^{W}, m_{j}^{W}, u_{j}^{W}\right)-\left(l_{B j}, m_{B j}, u_{B j}\right)\right| \leq\left(k^{*}, k^{*}, k^{*}\right) \\
\left|\left(l_{j}^{w}, m_{j}^{w}, u_{j}^{w}\right) /\left(l_{W}^{w}, m_{W}^{w}, u_{W}^{w}\right)-\left(l_{j W}, m_{j W}, u_{j W}\right)\right| \leq\left(k^{*}, k^{*}, k^{*}\right) \\
\sum_{j=1}^{n} R\left(w_{j}\right)=1 \\
l_{j}^{w} \leq m_{j}^{w} \leq u_{j}^{w} \\
l_{j}^{w} \geq 0 \\
j=1,2, \ldots, n
\end{array}\right.
$$

Equation (3) is solved for calculating the optimal fuzzy weights $\left(\tilde{w}_{1}^{*}, \tilde{w}_{2}^{*}, \ldots, \tilde{w}_{n}^{*}\right)$. A consistency check is applied as in Guo and Zhang [22] after obtaining the optimal fuzzy weights.

\begin{tabular}{|l|l|}
\hline \multicolumn{2}{|c|}{$\mathrm{X}_{1}$} \\
\hline States & Probability \\
\hline State $O$ & \\
\hline State 1 & \\
\hline
\end{tabular}
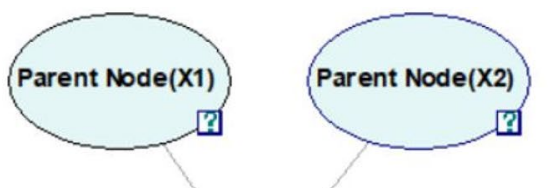

\begin{tabular}{|l|l|}
\hline \multicolumn{2}{|c|}{$\mathrm{X}_{2}$} \\
\hline States & Probability \\
\hline State $O$ & \\
\hline State 1 & \\
\hline
\end{tabular}

Chid Node

(X3)

?

\begin{tabular}{|l|c|c|c|c|}
\hline & \multicolumn{4}{|c|}{ Conditional probability table of $\left(\mathrm{X}_{3}\right)$} \\
\hline Parent Node $\mathrm{X}_{1}$ & \multicolumn{2}{|c|}{ State 0} & \multicolumn{2}{c|}{ State 1} \\
\hline Parent Node $\mathrm{X}_{2}$ & State 0 & State 1 & State 0 & State 1 \\
\hline State 0 & & & & \\
\hline State 1 & & & & \\
\hline
\end{tabular}

Fig. 2 A basic example of BN 


\section{Fuzzy Bayesian network (FBN)}

The Bayesian network (BN) method is a visual tool that is based on probability theory. In this method, a directed acyclic graph is used for demonstrating the quantity of variables and their dependency relationships $[16,51]$. This method is frequently used to explain uncertainty [5]. Its notions consist of nodes and arrows. While nodes show a random variable, arrows refer to the relationship between the variables [21, $59,60]$. In a BN, the nodes with arrows pointing towards them are called child nodes and the nodes with arrows pointing outwards from themselves are called parent nodes [32]. A node with child nodes but no parent nodes is called a root node. Figure 2 demonstrates the basic idea under BN concept.

In the example given by Fig. 2, both $X_{1}$ and $X_{2}$ are root nodes and they are the parent nodes of $\mathrm{X}_{3} . \mathrm{X}_{3}$ is a child of $X_{1}$ and $X_{2}$. Each node has two states: 'state 0 ' and 'state 1'. A root node has only a marginal probability. Each child has a conditional probability table associated with it showing the states of its parent nodes (Liu et al. [34]) (Table 3).

In a usual BN demonstration, some formulas are used as in the following [60]. The formula in the following equation shows the joint probability value:

$P\left(X_{1}, X_{2}, \ldots, X_{n}\right)=\prod_{1}^{n} P\left(X_{i} \mid \pi_{i}\right)(i=1,2, \ldots, n)$

Here, $\pi_{i}$ is the set of parents of node $X_{i}$. The marginal probability of $X_{i}$ is

$P\left\{X_{i}\right\}=\sum_{\text {except } X_{i}} P\left\{X_{1}, X_{2}, \ldots, X_{n}\right\}$.

As an inferential tool, BN calculates the probability of an event given other evidences. The following formulae shows the calculation procedure for the posterior probability of evidence $e$ :

$P(U \mid e)=\frac{P(e \mid U) P(U)}{P(e)}=\frac{P(e \mid U) P(U)}{\sum_{U} P(e \mid \mathrm{U}) P(\mathrm{U})}, U=\left\{X_{1}, X_{2}, \ldots, X_{n}\right\}$

Here,

$P(U)$ : the prior probability of event $U$,

Table 3 The linguistic variables of decision makers

\begin{tabular}{ll}
\hline Linguistic term & Corresponding TFN \\
\hline Equally importance (EI) & $(1,1,1)$ \\
Weakly important (WI) & $(2 / 3,1,1.5)$ \\
Fairly important (FI) & $(1.5,2,2.5)$ \\
Very important (VI) & $(2.5,3,3.5)$ \\
Absolutely important (AI) & $(3.5,4,4.5)$ \\
\hline
\end{tabular}

$P(e)$ : the pre-defined posterior probability of the evidence, $P(U \mid e)$ : the posterior probability of evidence $e$,

$P(e \mid U)$ : the evidence likelihood of event $U$, and.

$\sum_{U} P(e \mid \mathrm{U}) P(\mathrm{U})$ : the joint probability distribution of $e$.

Besides the traditional form of BN modeling, there is also a fuzzy form of BN which is called fuzzy Bayesian Network (FBN). It presents uncertain information and decreases information loss [63]. In the scope of the current study, experts evaluate main FMs and auxiliary FMs with the aid of a fuzzy linguistic scale. Following a procedure which suggested by Aliabadi et al. [3], final occurrence probabilities of each FMs are obtained. Hereafter this step, BN modeling is generated and crisp failure probabilities are gained.

\section{The holistic approach}

The holistic approach which is the basis for the methodology of this study consists of four main stages. The initial stage is about preparation for failure analysis and control. In this stage, experts were determined from the enterprise. In addition, the main and auxiliary FMs were identified that cause faulty products in the enterprise. The second stage concerns with assigning importance weights to the FMEA parameters via FBWM. In this stage, preference values of each main FM are computed with respect to two of the FMEA parameters which are $\mathrm{S}$ and $\mathrm{D}$. The values regarding the remained risk parameter "O" are calculated via a different way as presented in the third stage in details. This way concerns a probabilistic approach including BN and fuzzy logic. When viewed from the probability perspective, each preference value of the failure event that may occur randomly can be evaluated as the probability of these events occurring. For this reason, FMs can be considered as random events and their preference values as probability functions [38]. In the third stage, first, each expert was evaluated considering their characteristics, and a weighting coefficient for each expert was calculated. Then, the BN was created considering the top event, main FMs, and auxiliary FMs which affects them. The linguistic assessments of experts in fuzzy environment that are used in $\mathrm{BN}$ modeling were collected and converted into actual failure occurrence probabilities according to the procedure of Aliabadi et al. [3]. The flowchart of this holistic approach is provided in Fig. 3. The detailed analysis of our case will be demonstrated in the following section.

\section{Case study}

\section{Description of the production process}

The production process regarding industrial kitchen equipment includes nine different steps as given in Fig. 4. The first step is measuring. In this section, the sheets to be cut are 


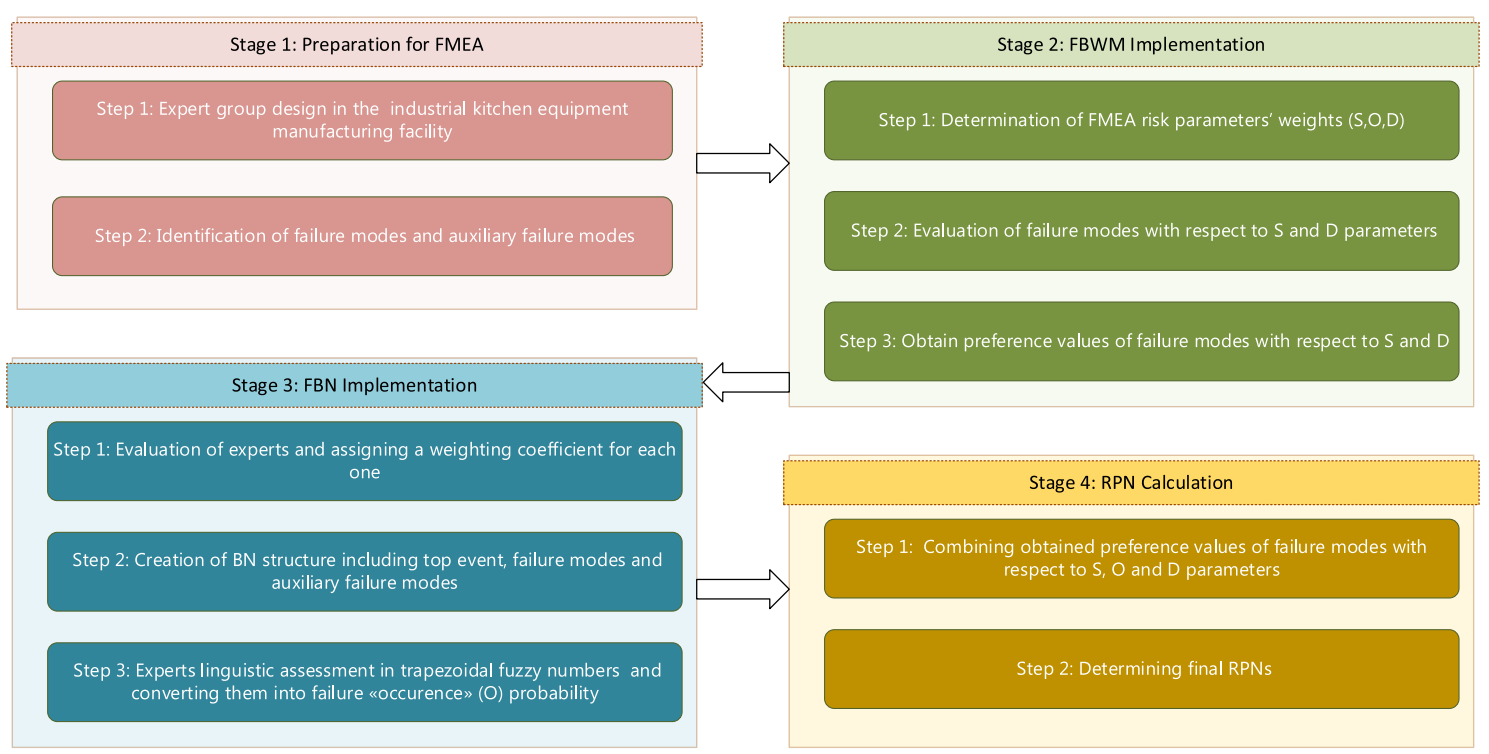

Fig. 3 The flow in the holistic approach

Fig. 4 Production stages for industrial kitchen equipment

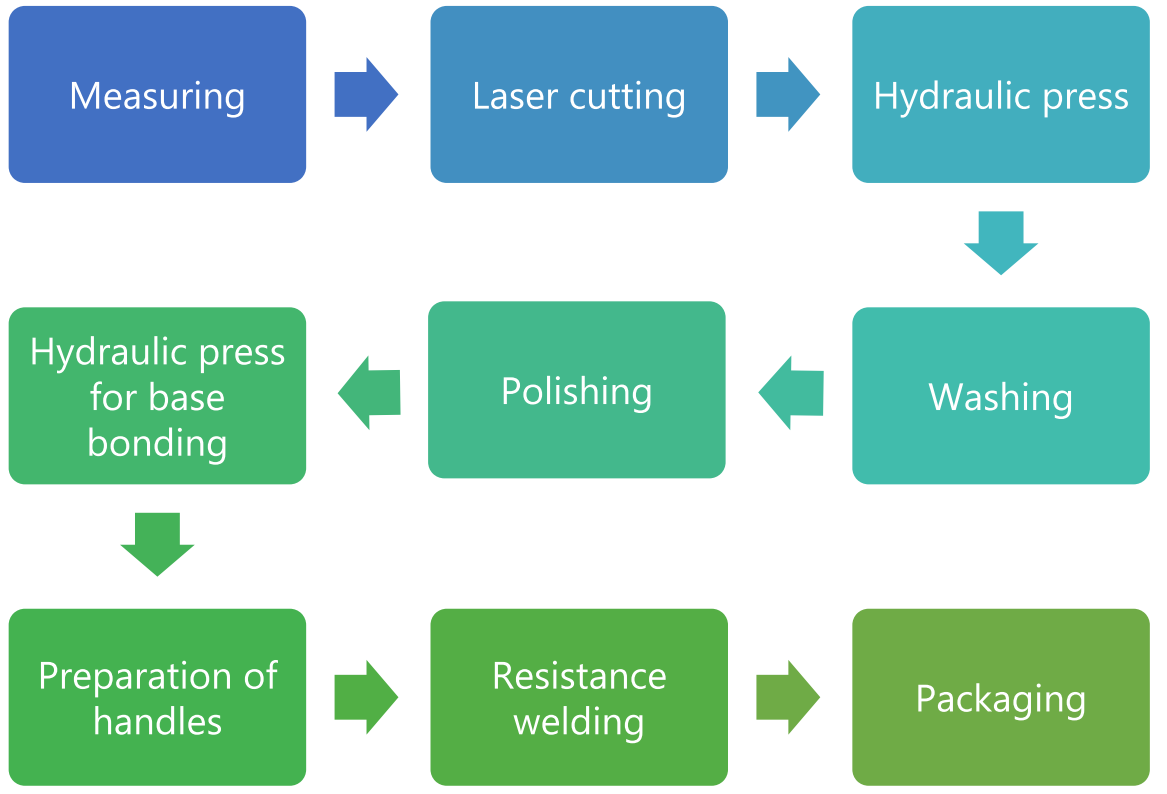

after washing. The outer surface becomes matte due to the processes performed. To remove this matting, the polishing process is applied to the outer surface. The hydraulic press is used again to connect the bottom of the operating pot with the side surfaces. Until these stages have been finalized, other parts of the pot, except for the handle part, have been completed. The handles of the pot are prepared and made ready for resistance welding. In the resistance welding section, the welding surfaces are cleaned by the operator. The current and welding time is adjusted by the operator. The welding surfaces are melted, and adhered to each other. It is packaged to protect ready products from external influences. prevent any oil residue on the metal. The products are dried 


\section{Identification of failure modes and their effects}

As a result of the evaluations made in the enterprise, five main FMs were identified. These FMs are stain on the product (FM1), polishing color difference on product (FM2), scratch on the product (FM3), cracking on the product (FM4), and failure in welding of pot handles properly (FM5). In addition, eight auxiliary FMs have been determined. These are as follows: Mismeasurement (X1), Wrong cutting (X2), Unsuitable mold (X3), Usage of unsuitable oil (X4), Overloading the hydraulic press (X5), Not choosing the proper brush (X6), Improper polishing (X7) and Unsuitable raw material (X8). Failures in industrial kitchen production cause the product to be scrapped or to be sold as a low-quality product, selling them below the sales price.

Stain on the product (FM1), usually takes place in the press section. If suitable oil is not selected during pressing, the material temperature cannot be lowered by distributing the heat throughout the plastic shape change of the material. In this case, it causes a permanent stain on the product. In addition, the resistance of the raw material to the deformation of plastic, in other words, its hardness, causes stains on the product. In addition, oil-raw material compatibility must be checked before production in large batches. Polishing color difference on the product (FM2) is directly related to the raw material and polishing application. In this section, the outer surface of the product is abraded with abrasive solutions, the product contact time with the solution should be adjusted very well. The fact that the materials sent by the suppliers do not always have the same characteristics, this requires a re-evaluation of the material-solution contact time. All products produced must be of the same color. When the consumer sees products of different colors, she/he thinks this is a manufacturing failure. Polishing failure does not cause any negative function of the product. However, this situation reduces the sales price of the product. Products with polishing failures are transferred to different sales channels. Scratch on the product (FM3), is closely related to brush selection. Scratches on the product may occur if a hard brush

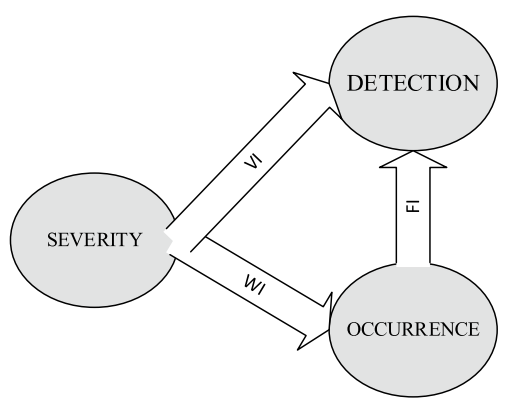

Fig. 5 Reference comparison in FBWM assessed by Expert 1 is selected. If a soft brush is chosen, the product will not be polished to the desired level. Cracking on the product (FM4) is closely related to overloading on the hydraulic press and wrong plate cutting. Wrong cut is due to wrong measurement and inappropriate mold usage. Overloading and wrong oil selection in the hydraulic press also causes the product to crack. Unlike the others, this failure makes the product completely unusable. If the product is cracked, the product is scrapped. Failure to weld pot handles properly (FM5), the reliability of this weld depends on the cleanliness of the weld surfaces, the electrode tips not oxidized and the correct electrode selection, and the good adjustment of the welding current and time.

\section{Implementation of FBWM}

The FBWM implementation stage (second stage) concerns with assigning importance weights to the FMEA parameters. In this stage, the preference values of each main FM are also computed with respect to two of the FMEA parameters which are severity (S) and detection (D).

Table 4 Defuzzified weight values of FMEA risk parameters assessed by six experts

\begin{tabular}{llll}
\hline Expert ID & $\mathrm{S}$ & $\mathrm{O}$ & $\mathrm{D}$ \\
\hline Expert 1 & 0.461 & 0.372 & 0.167 \\
Expert 2 & 0.302 & 0.597 & 0.101 \\
Expert 3 & 0.550 & 0.249 & 0.201 \\
Expert 4 & 0.428 & 0.428 & 0.144 \\
Expert 5 & 0.302 & 0.597 & 0.101 \\
Expert 6 & 0.194 & 0.479 & 0.327 \\
\hline
\end{tabular}

0.500
0.450
0.400
0.350
0.300
0.250
0.200
0.150
0.100
0.050
0.000

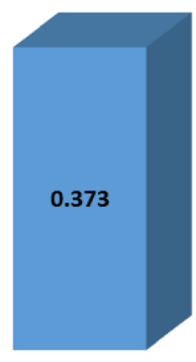

Severity

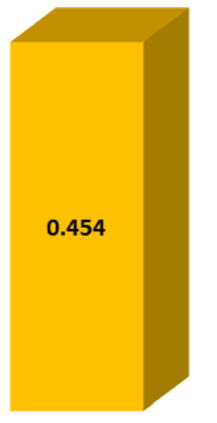

Occurrence

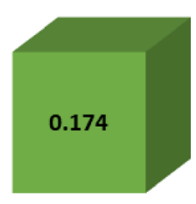

Detection
Fig. 6 Importance weights of FMEA parameters obtained from FBWM implementation 


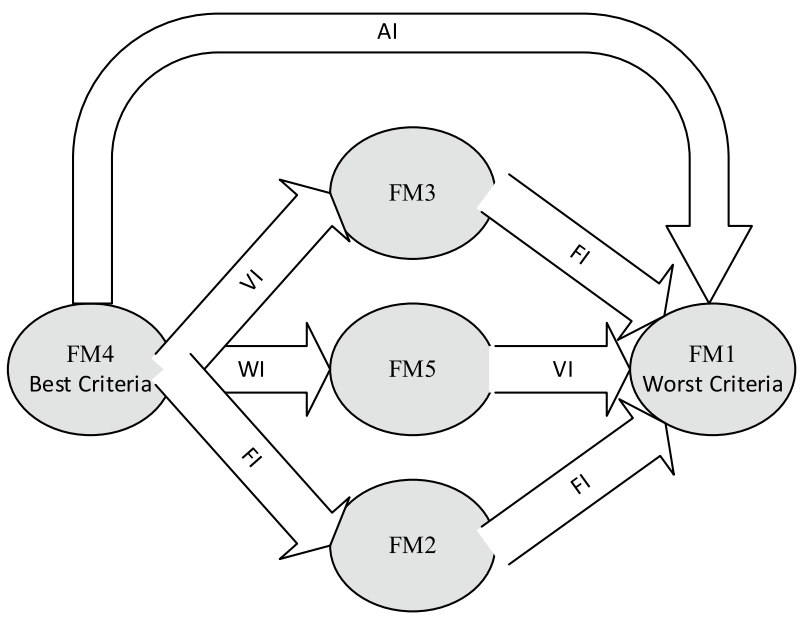

Fig. 7 Evaluation of main FMs with respect to S parameter by Expert 1

\section{Determination of importance weights of FMEA parameters}

In the second stage of the holistic approach, evaluations were made by six experts to determine importance weights for $\mathrm{S}, \mathrm{O}$ and $\mathrm{D}$ parameters. FBWM was used to make calculations. As an example, the evaluation of an expert is presented in Fig. 5.

The optimal fuzzy weights of three FMEA parameters assessed by one expert are calculated as follows: $w_{S}^{*}=(0.391,0.463,0.520) \quad, \quad w_{O}^{*}=(0.300,0.374,0.435)$ ,$w_{D}^{*}=(0.160,0.168,0.173)$. Then, the crisp weights are determined as follows: $w_{S}=(0.460), w_{O}=(0.372)$ ,$w_{D}=(0.167)$. Similarly, the evaluations made by other experts were calculated and presented in Table 4. By averaging these values, the weight values for each parameter are computed as in Fig. 6.

\section{Determination of priority values of FMs in terms of severity and detection parameters}

Similarly, all FMs were evaluated with respect to S and D parameters. As an example, the evaluation of Expert 1 with respect to $\mathrm{S}$ parameter is presented in Fig. 7. Other evaluations cannot be included in the paper due to space limitations. The preference values of each main FM are computed with respect to two of the FMEA parameters which are $\mathrm{S}$ and
Table 5 The preference values of five FM according to $\mathrm{S}$ and $\mathrm{D}$ parameters assessed by each expert

Fig. 8 The averaged preference values of FMs according to $S$ and $\mathrm{D}$ parameters

\begin{tabular}{|c|c|c|c|c|c|c|c|c|c|c|c|}
\hline & \multicolumn{5}{|c|}{ Severity (S) } & & \multicolumn{5}{|c|}{ Detection (D) } \\
\hline & FM1 & FM2 & FM3 & FM4 & FM5 & & FM1 & FM2 & FM3 & FM4 & FM5 \\
\hline Expert 1 & 0.096 & 0.164 & 0.108 & 0.355 & 0.277 & Expert 1 & 0.339 & 0.233 & 0.221 & 0.111 & 0.095 \\
\hline Expert 2 & 0.096 & 0.108 & $0.164 \mathrm{ss}$ & 0.355 & 0.277 & Expert 2 & 0.378 & 0.153 & 0.253 & 0.109 & 0.108 \\
\hline Expert 3 & 0.108 & 0.096 & 0.164 & 0.355 & 0.277 & Expert 3 & 0.339 & 0.233 & 0.221 & 0.111 & 0.095 \\
\hline Expert 4 & 0.164 & 0.096 & 0.108 & 0.355 & 0.277 & Expert 4 & 0.277 & 0.355 & 0.108 & 0.164 & 0.096 \\
\hline Expert 5 & 0.087 & 0.112 & 0.187 & 0.289 & 0.325 & Expert 5 & 0.253 & 0.153 & 0.378 & 0.108 & 0.109 \\
\hline Expert 6 & 0.132 & 0.108 & 0.132 & 0.224 & 0.405 & Expert 6 & 0.253 & 0.153 & 0.378 & 0.108 & 0.109 \\
\hline
\end{tabular}

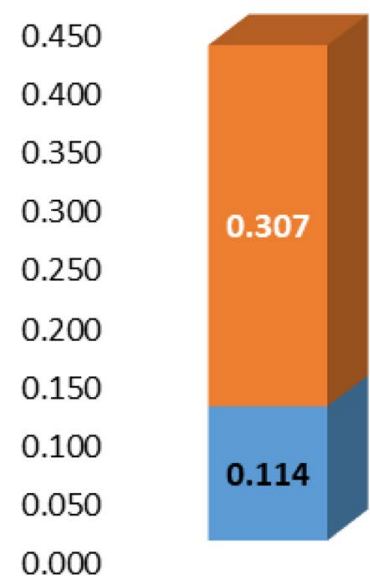

FM1

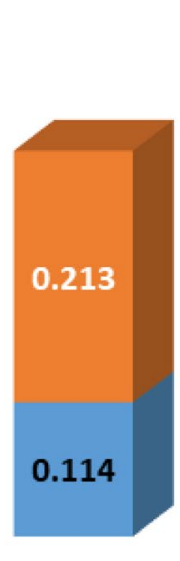

FM2
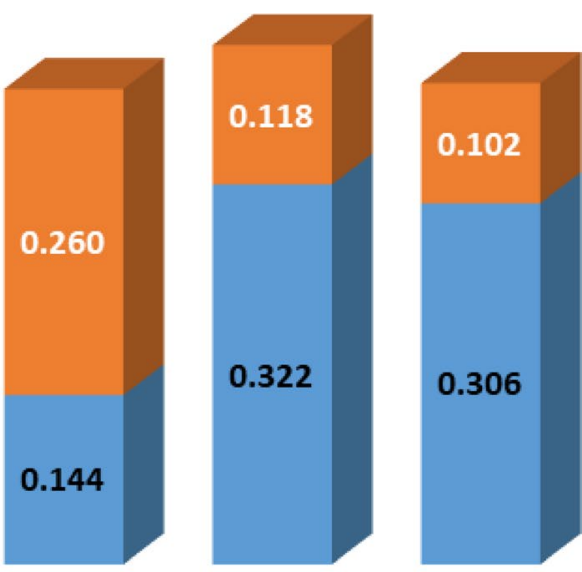

FM3

FM4

FM5 


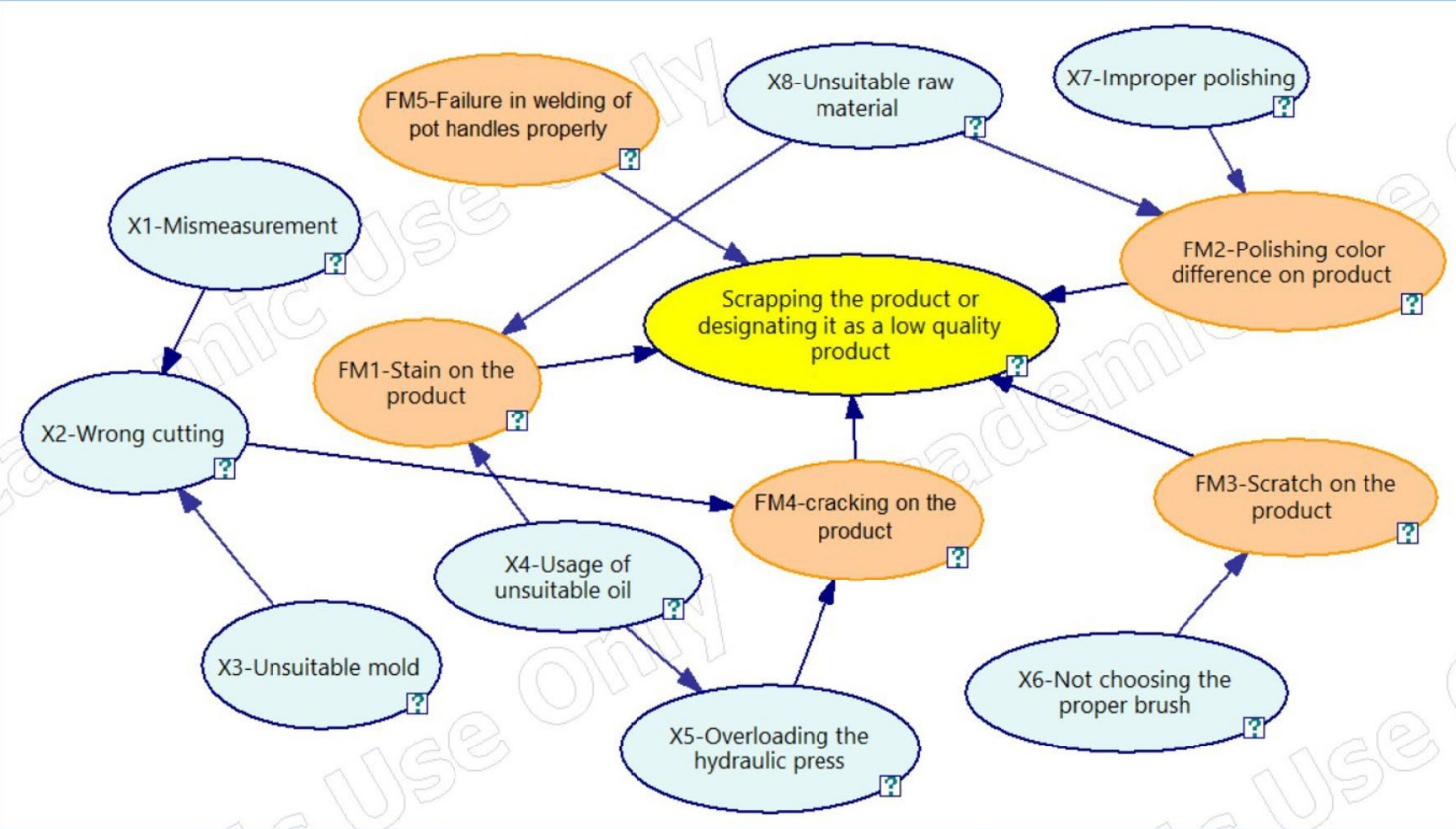

Fig. 9 The BN structure

D. The obtained results are presented in Table 5. By averaging the values in Table 5, the preference values of five FMs according to $\mathrm{S}$ and $\mathrm{D}$ parameters are presented in Fig. 8.

\section{Implementation of FBN}

The values regarding the remained risk parameter "occurrence $(\mathrm{O})$ " are calculated via a different way as presented by Aliabadi et al. [3]. This procedure and its computational steps are given in this stage. The BN structure of main failures and auxiliary failures is presented in Fig. 9. As seen from the Fig. 9, the top event concerns with scrapping the product or designating it as a low-quality product. This will probably cause a selling below the sales price. There are seven root nodes (basic events) in the $\mathrm{BN}$. These are $\mathrm{X} 1, \mathrm{X} 3$, X4, X6, X7, X8 and FM5. The remaining are child nodes and they have their own conditional probability table associated with its parent nodes.
We used GeNle commercial software (version 3.0) which was developed by Decision Systems Laboratory, University of Pittsburgh. Failure probability of basic events can be calculated by expert evaluation. In our case, the evaluations of six experts are considered. These experts are working as engineer, operator and technician. Their years of experience are varied between 4 and 15 years. While Expert 2 and Expert 5 have bachelor degree, Expert 1 has a Ph.D. degree on engineering. The weight factor is the sum of the coefficient of job title, years of experience, and educational level. The weighting coefficient is calculated by giving a grade to each feature (job title, year of experience, education level) between 1 to 5. For example, the weight factor of Expert 1 is 13 and the total weight factor is 45 . Then, by dividing these two values, a weighting coefficient of Expert 1 is calculated as $(13 / 45=0.29)$. The weighting coefficients of all experts are presented in the last column of Table 6.

Table 6 The information of the experts

\begin{tabular}{|c|c|c|c|c|c|c|c|c|}
\hline Expert ID & Job title & $\begin{array}{l}\text { Years of } \\
\text { experience }\end{array}$ & Educational level & $\begin{array}{l}\text { Job title } \\
\text { grade }(1-5)\end{array}$ & $\begin{array}{l}\text { Years of experi- } \\
\text { ence grade }(1-5)\end{array}$ & $\begin{array}{l}\text { Education level } \\
\text { grade (1-5) }\end{array}$ & Weight factor & $\begin{array}{l}\text { Weighting } \\
\text { coefficient }\end{array}$ \\
\hline Expert 1 & Chief engineer & 15 & $\mathrm{PhD}$ & 5 & 3 & 5 & $13 / 45$ & 0.29 \\
\hline Expert 2 & Engineer & 10 & $\mathrm{BSc}$ & 3 & 3 & 3 & $9 / 45$ & 0.20 \\
\hline Expert 3 & Operator & 10 & High school & 1 & 3 & 1 & $5 / 45$ & 0.11 \\
\hline Expert 4 & Technician & 5 & Vocational school & 2 & 1 & 2 & $5 / 45$ & 0.11 \\
\hline Expert 5 & Engineer & 8 & $\mathrm{BSc}$ & 3 & 2 & 3 & $8 / 45$ & 0.18 \\
\hline Expert 6 & Technician & 4 & Vocational school & 2 & 1 & 2 & $5 / 45$ & 0.11 \\
\hline
\end{tabular}




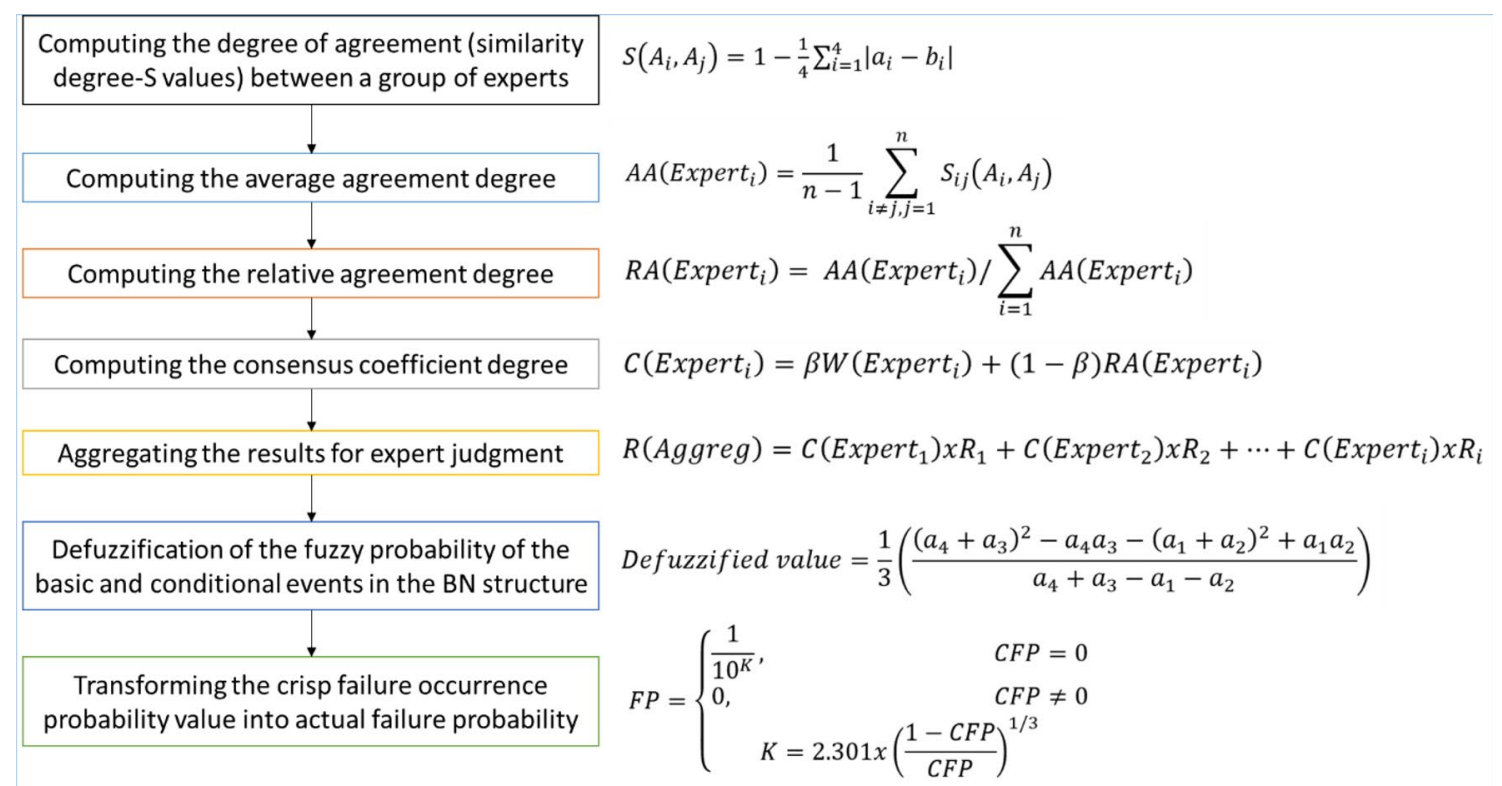

Fig. 10 The procedure of the aggregation used in expert judgments in FBN

To obtain crisp failure occurrence probabilities using FBN, a procedure suggested by Aliabadi et al. [3] is followed. This procedure can easily aggregate the linguistic evaluations of experts and reach a consensus in finding crisp failure probabilities of main FMs. The steps in this procedure are given in Fig. 10. In the first step of this procedure, the degree of agreement between two experts among a group of experts is computed using the corresponding formulae. In the formulae, $A_{i}$ and $A_{j}$ refer to two different linguistic variables that are presented in trapezoidal fuzzy numbers style. $A_{i}=\left(a_{1}, a_{2}, a_{3}, a_{4}\right)$ and $A_{j}=\left(b_{1}, b_{2}, b_{3}, b_{4}\right)$. In the second and third steps, the average agreement degrees (AA values) and relative agreement degrees (RA values) are computed, respectively. In the fourth step, consensus coefficient degrees ( $\mathrm{C}$ values) of experts are calculated using the related formulae. Here, $\beta$ is a factor which shows the importance of weight coefficients of experts over RA(Expert $\left.{ }_{i}\right)$. Its values vary between 0 and 1 . In the fifth step, the aggregated results of the experts are obtained. Here, $R_{i}$ refers to the fuzzy probability assigned by an expert. In the sixth step, the fuzzy probability of the basic and conditional events is crispified. Finally, the crisp failure occurrence probability (CFP) values are transformed into actual failure occurrence probability (FP) values using the formulae in Fig. 10. At the end of the implementation of this procedure, all calculations related to the occurrence probability values have been made. Due to space limitations in this study, we have attached them as a Supplementary file. These values cover evaluations of just one parameter of FMEA ("occurrence" parameter). Expert assessments on the other two parameters (severity and detection) of FMEA have been made via
Table 7 The linguistic scale in trapezoidal fuzzy numbers

\begin{tabular}{ll}
\hline Linguistic term & Trapezoidal fuzzy number \\
\hline Very low (VL) & $(0,0,0.1,0.2)$ \\
Low (L) & $(0.1,0.2,0.2,0.3)$ \\
Mildly low (ML) & $(0.2,0.3,0.4,0.5)$ \\
Medium (M) & $(0.4,0.5,0.5,0.6)$ \\
Mildly high (MH) & $(0.5,0.6,0.7,0.8)$ \\
High (H) & $(0.7,0.8,0.8,0.9)$ \\
Very high (VH) & $(0.8,0.9,1.0,1.0)$ \\
\hline
\end{tabular}

FBWM method in "Determination of priority values of FMs in terms of severity and detection parameters". In addition, parameter weights of FMEA are assessed by experts and a weight matrix for them has been gained in "Determination of importance weights of FMEA parameters". Then, merging of both matrices, final RPN values of each failure mode can be computed. This will be explained in the next section ("Determination of FM scores").

In this procedure, the linguistic variables which the experts used for evaluation of basic events and their corresponding trapezoidal fuzzy numbers are presented in Table 7.

The evaluation of experts for each basic event in the constructed BN (shown in Fig. 9) is presented in Table 8. These evaluations are considered as input in the aggregation procedure. Then, the aggregation operator is applied for each basic event. We presented the details of aggregation for basic events X1 in Table 9.

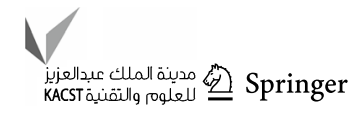


Table 8 The expert evaluation on basic events

\begin{tabular}{llllllll}
\hline & X1 & X3 & X4 & X6 & X7 & X8 & FM5 \\
\hline Expert 1 & ML & L & L & L & M & ML & L \\
Expert 2 & VL & VL & L & VL & MH & ML & L \\
Expert 3 & L & VL & L & L & MH & ML & ML \\
Expert 4 & M & L & M & L & H & ML & M \\
Expert 5 & M & L & L & M & MH & MH & L \\
Expert 6 & M & L & L & L & H & MH & VL \\
\hline
\end{tabular}

Table 9 The aggregation procedure for basic event X1

\begin{tabular}{|c|c|c|c|c|c|}
\hline \multirow{2}{*}{$\begin{array}{l}\text { Experts } \\
\text { Expert } 1\end{array}$} & \multirow{2}{*}{$\begin{array}{l}\text { Linguistic } \\
\text { judgment }\end{array}$} & \multicolumn{4}{|c|}{ Trapezoidal fuzzy number } \\
\hline & & 0.2 & 0.3 & 0.4 & 0.5 \\
\hline Expert 2 & $\mathrm{VL}$ & 0.0 & 0.0 & 0.1 & 0.2 \\
\hline Expert 3 & $\mathrm{~L}$ & 0.1 & 0.2 & 0.2 & 0.3 \\
\hline Expert 4 & M & 0.4 & 0.5 & 0.5 & 0.6 \\
\hline Expert 5 & M & 0.4 & 0.5 & 0.5 & 0.6 \\
\hline Expert 6 & M & 0.4 & 0.5 & 0.5 & 0.6 \\
\hline$S(1-2)$ & 0.725 & AA $\left(\right.$ Expert $\left._{1}\right)$ & 0.825 & & \\
\hline $\mathrm{S}(1-3)$ & 0.850 & AA $\left(\right.$ Expert $\left._{2}\right)$ & 0.665 & & \\
\hline $\mathrm{S}(1-4)$ & 0.850 & AA $\left(\right.$ Expert $\left._{3}\right)$ & 0.765 & & \\
\hline $\mathrm{S}(1-5)$ & 0.850 & AA $\left(\right.$ Expert $\left._{4}\right)$ & 0.825 & & \\
\hline$S(1-6)$ & 0.850 & AA $\left(\right.$ Expert $\left._{5}\right)$ & 0.825 & & \\
\hline$S(2-3)$ & 0.875 & AA $\left(\right.$ Expert $\left._{6}\right)$ & 0.825 & & \\
\hline$S(2-4)$ & 0.575 & $\mathrm{C}\left(\right.$ Expert $\left._{1}\right)$ & 0.232 & & \\
\hline$S(2-5)$ & 0.575 & $\mathrm{C}\left(\right.$ Expert $\left._{2}\right)$ & 0.170 & & \\
\hline$S(2-6)$ & 0.575 & $\mathrm{C}\left(\right.$ Expert $\left._{3}\right)$ & 0.136 & & \\
\hline S (3-4) & 0.700 & $\mathrm{C}\left(\right.$ Expert $\left._{4}\right)$ & 0.142 & & \\
\hline $\mathrm{S}(3-5)$ & 0.700 & $\mathrm{C}\left(\right.$ Expert $\left._{5}\right)$ & 0.177 & & \\
\hline S (3-6) & 0.700 & $\mathrm{C}\left(\right.$ Expert $\left._{6}\right)$ & 0.142 & & \\
\hline$S(4-5)$ & 1.000 & $\mathrm{~A} 1$ & 0.245 & & \\
\hline$S(4-6)$ & 1.000 & $\mathrm{~A} 2$ & 0.328 & & \\
\hline$S(5-6)$ & 1.000 & A3 & 0.368 & & \\
\hline RA $\left(\right.$ Expert $\left._{1}\right)$ & 0.174 & A4 & 0.468 & & \\
\hline RA $\left(\right.$ Expert $\left._{2}\right)$ & 0.141 & $\mathrm{~K}$ & 2.815 & & \\
\hline RA $\left(\right.$ Expert $\left._{3}\right)$ & 0.162 & CFP & 0.353 & & \\
\hline RA (Expert $\left.{ }_{4}\right)$ & 0.174 & FP & 0.001 & & \\
\hline RA (Expert $\left.{ }_{5}\right)$ & 0.174 & & & & \\
\hline RA (Expert 6$)$ & 0.174 & & & & \\
\hline
\end{tabular}

Table 10 The occurrence probability for conditional event $\mathrm{X} 2$ case

\begin{tabular}{llllll}
\hline If $X 1$ is & No & & \multicolumn{1}{l}{ Yes } & \\
\cline { 2 - 3 } \cline { 5 - 6 } If $X 3$ is & No & Yes & & No & Yes \\
\hline If X2 is No & 0.999 & 0.939 & & 0.947 & 0.902 \\
If X2 is Yes & 0.001 & 0.061 & & 0.053 & 0.098 \\
\hline
\end{tabular}

Table 11 The results of FBN

\begin{tabular}{lll}
\hline FM & Occurrence probability & $\begin{array}{l}\text { Normalized } \\
\text { occurrence prob- } \\
\text { ability }\end{array}$ \\
\hline FM1 & 0.001511 & 0.194 \\
FM2 & 0.001700 & 0.218 \\
FM3 & 0.003045 & 0.391 \\
FM4 & 0.001097 & 0.141 \\
FM5 & 0.000430 & 0.055 \\
\hline
\end{tabular}

In addition, the conditional probabilities of the nodes are also calculated. For example, if the basic events of X1 and $\mathrm{X} 3$ have occurred, the occurrence probability of conditional event $\mathrm{X} 2$ is calculated as 0.902 . In the same manner, all possible situations are presented in Table 10.

The occurrence probabilities of FMs are then calculated, and they are given in Table 11. FM3 is determined as FM with the highest occurrence probability. Then, occurrence probabilities obtained using FBN were normalized to become suitable for matrix multiplication and comparative study.

\section{Determination of FM scores}

Two matrices are used in the RPN calculation of five FMs. The first matrix consists of three columns. The first and third columns consist of averaged preference values of FMs according to $S$ and $D$ parameters as presented in Fig. 7. The second column contains the normalized occurrence probabilities as given in Table 10. The second matrix includes the importance weights of FMEA parameters obtained from FBWM implementation as given in Fig. 5. By multiplying these two matrices, RPNs are obtained as follows:

$\left[\begin{array}{lll}0.114 & 0.194 & 0.307 \\ 0.114 & 0.218 & 0.213 \\ 0.144 & 0.391 & 0.260 \\ 0.322 & 0.141 & 0.118 \\ 0.306 & 0.055 & 0.102\end{array}\right] \times\left[\begin{array}{l}0.372 \\ 0.454 \\ 0.174\end{array}\right]=\left[\begin{array}{l}0.184 \\ 0.179 \\ 0.276 \\ 0.205 \\ 0.157\end{array}\right]$


Scratch on the product (FM3) has been calculated with the highest risk value of 0.276 . The occurrence of this risk does not make the product scrapped, but service sectors such as hotels and restaurants avoid buying such faulty products. Therefore, the price of products with this defect drops dramatically. Cracking on the product (FM4) has been calculated as the second-highest risk value 0.204. In this case, the product is no longer usable in any way and is sent for scrap. The third highest risk has been calculated 0.183 stain on the product (FM1). Although FM1 causes a decrease in the price of the product due to cosmetic reasons similar to FM3, its effect is more limited than FM3. The fourth highest risk has been calculated 0.204 polishing color difference on the product (FM4). This risk is similar to FM1 and FM3. However, its effect is much more limited than others. This color difference can only be evaluated by experts. Generally, this situation is noticed during and after product delivery, negatively affects the brand image in the long term. The lowest risk was calculated as Failure to weld pot handles properly (FM5) with 0.157 . The occurrence of this risk makes the product unusable and unsold, but it is easy to detect. In addition, technological developments in resistance welding, especially in recent years, have considerably reduced the possibility of faulty welding.

\section{Comparative study}

In our proposed approach, preference values of FMs with respect to parameters $S$ and $D$ were obtained via FBWM. Then, the preference values of FMs with respect to parameter $O$ were obtained via FBN-based procedure. To test the validity of the proposed holistic approach, a benchmarking approach which considers evaluations of FMs with respect to all of the three parameters via FBWM is demonstrated. Table 12 shows the preference values of five FMs according to parameter $O$ assessed by each expert. Preference values of FMs with respect to parameters $S$ and $D$ are given in Table 5 .

Table 12 The preference values of five FM according to "occurrence" parameter assessed by each expert

\begin{tabular}{llllll}
\hline Expert & \multicolumn{6}{l}{ Occurrence probability $(O)$} \\
\cline { 2 - 6 } & FM1 & FM2 & FM3 & FM4 & FM5 \\
\hline Expert 1 & 0.251 & 0.140 & 0.365 & 0.103 & 0.140 \\
Expert 2 & 0.132 & 0.224 & 0.405 & 0.108 & 0.132 \\
Expert 3 & 0.153 & 0.378 & 0.253 & 0.109 & 0.108 \\
Expert 4 & 0.153 & 0.371 & 0.229 & 0.142 & 0.105 \\
Expert 5 & 0.339 & 0.233 & 0.221 & 0.095 & 0.111 \\
Expert 6 & 0.378 & 0.153 & 0.253 & 0.109 & 0.108 \\
Averaged & 0.234 & 0.250 & 0.288 & 0.111 & 0.117 \\
\hline
\end{tabular}

Table 13 Results of comparative study

\begin{tabular}{|c|c|c|c|c|}
\hline \multirow[t]{2}{*}{ FM } & \multicolumn{2}{|c|}{ Proposed approach } & \multicolumn{2}{|c|}{$\begin{array}{l}\text { Benchmarking } \\
\text { approach }\end{array}$} \\
\hline & RPN & Rank & RPN & Rank \\
\hline FM1 & 0.184 & 3 & 0.202 & 2 \\
\hline FM2 & 0.179 & 4 & 0.193 & 3 \\
\hline FM3 & 0.276 & 1 & 0.229 & 1 \\
\hline FM4 & 0.205 & 2 & 0.191 & 4 \\
\hline FM5 & 0.157 & 5 & 0.185 & 5 \\
\hline
\end{tabular}

By combining Tables 12 and (the averaged values), the first matrix is gained as in the following. Then, new RPNs were obtained by multiplying these two matrices. In the obtained results, it starts with RPN for FM1 in the first row of the matrix (a value of 0.202 ) and ends with RPN value for FM5 in the 5th row (a value of 0.185 ):

$\left[\begin{array}{lll}0.114 & 0.234 & 0.307 \\ 0.114 & 0.250 & 0.213 \\ 0.144 & 0.288 & 0.260 \\ 0.322 & 0.111 & 0.118 \\ 0.306 & 0.117 & 0.102\end{array}\right] \times\left[\begin{array}{l}0.372 \\ 0.454 \\ 0.174\end{array}\right]=\left[\begin{array}{l}0.202 \\ 0.193 \\ 0.229 \\ 0.191 \\ 0.185\end{array}\right]$

As a result of the calculation, FM ranks are as follows: RPN3 $>$ PRN1 $>$ RPN2 $>$ PRN4 $>$ RPN5. When the values of this RPN calculation procedure and the proposed holistic approach are compared, it is observed that the ranks are similar. The comparison results are provided in Table 13. Pearson correlation coefficient regarding ranks in both approaches was determined as 0.998 . In this case, it can be said that there is a very strong relationship between the two rankings.

\section{Conclusion}

Industrial kitchen equipment is used in many commercial and non-commercial organizations such as hotels, airports, universities, shopping malls, and laboratories. The service industry plays the most important role in the rise of industrial kitchen equipment. In parallel with the development of the service industry, industrial kitchen equipment production is also developing. Companies need to increase their quality and reduce their sales prices in order to compete in the market. For this reason, the failure analysis can be a guide in reducing the number of scrap products and increasing product quality. FMEA is one of the most frequently used failure analysis tools in the decision-making process of different industry types and operations, and it enables decisionmakers to make critical decisions easier. 
In this study, a failure analysis is performed for the industrial kitchen equipment production. Failures in the manufacturing process have not been easily predictable, and the complexity required a change in the traditional FMEA concept. While this traditional RPN logic may seem like a methodical way to rank failures in system safety assessment, it has many disadvantages handled in the literature up to now. Therefore, in this study, an FMEA with a holistic FBN and FBWM approach is proposed. FBWM has been injected into the proposed holistic approach to assign importance weights to the three risk parameters of FMEA and to obtain preference values of FMs with respect to $S$ and $D$ parameters. In addition, the FBN is used to find the actual occurrence probability values of FMs. Finally, obtained preference values of FMs with respect to all three risk parameters from both FBWM and FBN are then merged to determine final RPN of each FM.

This study has revealed a general risk analysis of the production process for the observed production facility considering all product types. In this industry, dozens of product types are produced and the production process of each product changes slightly. For future studies, a separate BN can be created for each product type. This constructed BN should include main and auxiliary FMs of each product type. Thus, it will be possible to generate a more representative FMEA for the facility, as each product type is produced in different quantities.

Another limitation of the study is that the company have not analyzed the causes of failures in the previous period and not kept the records systematically. The availability of past records would allow a more efficient computation with precise data on the FMEA parameters. Another suggestion for future studies is that the weights of the risk parameters as well as each FM can be calculated with other MCDM methods. Thus, the results obtained not only with FBWM but also from other methods will guide decision-makers.

Supplementary Information The online version contains supplementary material available at https://doi.org/10.1007/s40747-021-00279-z.

\section{Compliance with ethical standards}

Conflict of interest On behalf of all the authors, the corresponding author states that there is no conflict of interest.

Open Access This article is licensed under a Creative Commons Attribution 4.0 International License, which permits use, sharing, adaptation, distribution and reproduction in any medium or format, as long as you give appropriate credit to the original author(s) and the source, provide a link to the Creative Commons licence, and indicate if changes were made. The images or other third party material in this article are included in the article's Creative Commons licence, unless indicated otherwise in a credit line to the material. If material is not included in the article's Creative Commons licence and your intended use is not permitted by statutory regulation or exceeds the permitted use, you will need to obtain permission directly from the copyright holder. To view a copy of this licence, visit http://creativecommons.org/licenses/by/4.0/.

\section{References}

1. (URL-1) https://www.transparencymarketresearch.com/comme rcial-cooking-equipment-market.html Commercial Cooking Equipment Market- Global Industry Analysis, Size, Share, Growth, Trends and Forecast 2018-2026.

2. (URL-2) https://www.grandviewresearch.com/industry-analysis/ commercial-kitchen-equipment-appliances-market

3. Aliabadi MM, Pourhasan A, Mohammadfam I (2020) Risk modelling of a hydrogen gasholder using Fuzzy Bayesian Network (FBN). Int J Hydrogen Energy 45(1):1177-1186

4. Başhan, V., Demirel, H., \& Gul, M. (2020). An FMEA-based TOPSIS approach under single valued neutrosophic sets for maritime risk evaluation: the case of ship navigation safety. Soft Computing, 1-16.

5. Ben-Gal I. (2008). Bayesian networks. Encyclopedia of statistics in quality and reliability, 1.

6. Boodhun N, Jayabalan M (2018) Risk prediction in life insurance industry using supervised learning algorithms. Complex Intell Syst 4(2):145-154

7. Boral S, Howard I, Chaturvedi SK, McKee K, Naikan VNA (2020) An integrated approach for fuzzy failure modes and effects analysis using fuzzy AHP and fuzzy MAIRCA. Eng Fail Anal 108:104195

8. Bowles JB, Peláez CE (1995) Fuzzy logic prioritization of failures in a system failure mode, effects and criticality analysis. Reliabil Eng Syst Saf 50(2):203-213

9. Bozdag E, Asan U, Soyer A, Serdarasan S (2015) Risk prioritization in failure mode and effects analysis using interval type-2 fuzzy sets. Expert Syst Appl 42(8):4000-4015

10. Calori IC, \& Stalhane T (2007) FMEA and BBN for robustness analysis in web-based applications. In European Safety and Reliability Conference.

11. Chang KH, Chang YC, Tsai IT (2013) Enhancing FMEA assessment by integrating grey relational analysis and the decision making trial and evaluation laboratory approach. Eng Fail Anal 31:211-224

12. Chang TW, Lo HW, Chen KY, Liou JJ (2019) A novel FMEA model based on rough BWM and rough TOPSIS-AL for risk assessment. Mathematics 7(10):874

13. Chen C, Zhang L, Tiong RLK (2020) A novel learning cloud Bayesian network for risk measurement. Appl Soft Comput $87: 105947$

14. Cheng PF, Li DP, He JQ, Zhou XH, Wang JQ, Zhang HY (2020) Evaluating surgical risk using FMEA and MULTIMOORA methods under a single-valued trapezoidal neutrosophic environment. Risk Manage Healthcare Policy 13:865

15. Commercial Kitchen Appliances Market Size, Share \& Trends Analysis Report By Product (Refrigerator, Cooking Appliance, Dishwasher, Other Specialized Appliance), By End Use, By Region, And Segment Forecasts, 2020-2027.

16. Corriveau G, Guilbault R, Tahan A, Sabourin R (2016) Bayesian network as an adaptive parameter setting approach for genetic algorithms. Complex Intell Syst 2(1):1-22

17. Dezan C, Zermani S, Hireche C (2020) Embedded Bayesian network contribution for a safe missing planning of autonomous vehicles. Algorithms 13(7):155

18. Dorosti S, Fathi M, Ghoushchi SJ, Khakifirooz M, Khazaeili M (2020) Patient waiting time management through fuzzy based 
failure mode and effect analysis. J Intell Fuzzy Syst (Preprint) pp $1-12$

19. García A, Gilabert EDUARDO (2011) Mapping FMEA into Bayesian networks. Int J Perform Eng 7(6):525-537

20. Ghoushchi SJ, Yousefi S, Khazaeili M (2019) An extended FMEA approach based on the Z-MOORA and fuzzy BWM for prioritization of failures. Appl Soft Comput 81:105505

21. Gul M, Yucesan M, Celik E (2020) A manufacturing failure mode and effect analysis based on fuzzy and probabilistic risk analysis. Appl Soft Comput 96:106689

22. Guo S, Zhao H (2017) Fuzzy best-worst multi-criteria decision-making method and its applications. Knowl-Based Syst 121:23-31

23. Huang J, You JX, Liu HC, Song MS (2020) Failure mode and effect analysis improvement: s systematic literature review and future research agenda. Reliabil Eng Syst Saf. https://doi. org/10.1016/j.ress.2020.106885

24. Khalilzadeh M, Balafshan R, Hafezalkotob A (2020) Multiobjective mathematical model based on fuzzy hybrid multi-criteria decision-making and FMEA approach for the risks of oil and gas projects. J Eng Des Technol. https://doi.org/10.1108/ JEDT-01-2020-0020

25. Kirchhof M, Haas K, Kornas T, Thiede S, Hirz M, Hermann C (2020) Root Cause Analysis in Lithium-Ion Battery Production with FMEA-Based Large-Scale Bayesian Network. arXiv Preprint. https://doi.org/10.20944/preprints202012.0312.v1

26. Kolagar M, Hosseini SMH, Felegari R (2020) Developing a new BWM-based GMAFMA approach for evaluation of potential risks and failure modes in production processes. Int J Qual Reliabil Manage. https://doi.org/10.1108/IJQRM-09-2018-0230

27. Lee, B. H. (2001). Using Bayes belief networks in industrial FMEA modeling and analysis. In Annual Reliability and Maintainability Symposium. 2001 Proceedings. International Symposium on Product Quality and Integrity (Cat. No. 01CH37179) (pp. 7-15). IEEE.

28. Lee D, Choi D (2020) Analysis of the reliability of a starter-generator using a dynamic Bayesian network. Reliabil Eng Syst Saf 195:106628

29. Lian P, Ning N, Aiping C, Yaobin T (2010). Fault diagnosis of the blast furnace based on the Bayesian network model. In 2010 International Conference on Electrical and Control Engineering (pp. 990-993). IEEE.

30. Liu, H. C. (2016). FMEA using uncertainty theories and MCDM methods. In FMEA using uncertainty theories and MCDM methods (pp. 13-27). Springer, Singapore.

31. Liu HC, Hu YP, Wang JJ, Sun M (2018) Failure mode and effects analysis using two-dimensional uncertain linguistic variables and alternative queuing method. IEEE Trans Reliab 68(2):554-565

32. Liu Z, Liu Y (2019) A Bayesian network based method for reliability analysis of subsea blowout preventer control system. J Loss Prev Process Ind 59:44-53

33. Liu HC, Liu L, Liu N (2013) Risk evaluation approaches in failure mode and effects analysis: a literature review. Expert Syst Appl 40(2):828-838

34. Lo HW, Liou JJ (2018) A novel multiple-criteria decision-makingbased FMEA model for risk assessment. Applied Soft Computing 73:684-696

35. Lo HW, Shiue W, Liou JJ, Tzeng GH (2020) A hybrid MCDMbased FMEA model for identification of critical failure modes in manufacturing. Soft Comput 24:15733-15745

36. Ma D, Zhou Z, Jiang Y, Ding W (2014) Constructing bayesian network by integrating fmea with fta. In 2014 Fourth International Conference on Instrumentation and Measurement, Computer, Communication and Control (pp. 696-700). IEEE.
37. Mi X, Tang M, Liao H, Shen W, Lev B (2019) The state-of-the-art survey on integrations and applications of the best worst method in decision making: Why, what, what for and what's next? Omega $87: 205-225$

38. Mohammadi M, Rezaei J (2020) Bayesian best-worst method: A probabilistic group decision making model. Omega 96:102075

39. Moktadir MA, Ali SM, Kusi-Sarpong S, Shaikh MAA (2018) Assessing challenges for implementing Industry 4.0: Implications for process safety and environmental protection. Process Saf Environ Prot 117:730-741

40. Momen S, Tavakkoli-Moghaddam R, Ghasemkhani A, ShahnejatBushehri S, Tavakkoli-Moghaddam H (2019) Prioritizing Surgical Cancellation Factors Based on a Fuzzy Best-Worst Method: A Case Study. IFAC-PapersOnLine 52(13):112-117

41. Moslem S, Gul M, Farooq D, Celik E, Ghorbanzadeh O, Blaschke $\mathrm{T}$ (2020) An integrated approach of best-worst method (BWM) and triangular fuzzy sets for evaluating driver behavior factors related to road safety. Mathematics 8(3):414

42. Nie RX, Tian ZP, Wang XK, Wang JQ, Wang TL (2018) Risk evaluation by FMEA of supercritical water gasification system using multi-granular linguistic distribution assessment. KnowlBased Syst 162:185-201

43. Nie W, Liu W, Wu Z, Chen B, Wu L (2019) Failure mode and effects analysis by integrating Bayesian fuzzy assessment number and extended gray relational analysis-technique for order preference by similarity to ideal solution method. Quality and Reliability Engineering International 35(6):1676-1697

44. Ozdemir Y, Gul M, Celik E (2017) Assessment of occupational hazards and associated risks in fuzzy environment: a case study of a university chemical laboratory. Human and Ecol Risk Assess 23(4):895-924

45. Park J, Park C, Ahn S (2018) Assessment of structural risks using the fuzzy weighted Euclidean FMEA and block diagram analysis. Int J Adv Manufact Technol 99(9-12):2071-2080

46. Peko M, Komatina N, Banduka N, Crnjac M (2018) The assessment and ranking of failures in the information technology industry based on FMEA and MCDM. Ekonomski horizonti 20(3):257-268

47. Qin J, Xi Y, Pedrycz W (2020) Failure mode and effects analysis (FMEA) for risk assessment based on interval type-2 fuzzy evidential reasoning method. Appl Soft Comput 89:106134

48. Rastayesh S, Bahrebar S, Blaabjerg F, Zhou D, Wang H, Sørensen JD (2019) A system engineering approach using FMEA and Bayesian network for risk analysis-a case study. Sustainability 12(1):1-18

49. Rezaei J (2015) Best-worst multi-criteria decision-making method. Omega 53:49-57

50. Rezaei J (2016) Best-worst multi-criteria decision-making method: Some properties and a linear model. Omega 64:126-130

51. Song G, Khan F, Yang M (2019) Integrated risk management of hazardous processing facilities. Process Saf Prog 38(1):42-51

52. Stamatis, D. H. (2003). Failure mode and effect analysis: FMEA from theory to execution. Quality Press.

53. Taleb-Berrouane M, Khan F, Amyotte P (2020) Bayesian Stochastic Petri Nets (BSPN)-A new modelling tool for dynamic safety and reliability analysis. Reliabil Eng Syst Saf 193:106587

54. Tian ZP, Wang JQ, Zhang HY (2018) An integrated approach for failure mode and effects analysis based on fuzzy best-worst, relative entropy, and VIKOR methods. Appl Soft Comput 72:636-646

55. Wan C, Yan X, Zhang D, Qu Z, Yang Z (2019) An advanced fuzzy Bayesian-based FMEA approach for assessing maritime supply chain risks. Transport Res E 125:222-240

56. Yang S, Bian C, Li X, Tan L, Tang D (2018) Optimized fault diagnosis based on FMEA-style CBR and BN for embedded software system. The Int J Adv Manufact Technol 94(9-12):3441-3453

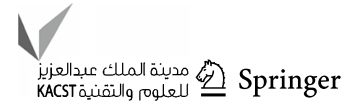


57. Yang S, Lu M, Liu B, Hao B (2009) A fault diagnosis model for embedded software based on FMEA/FTA and bayesian network. In: 2009 8th International Conference on Reliability, Maintainability and Safety, IEEE, pp 778-782

58. Yang Z, Bonsall S, Wang J (2008) Fuzzy rule-based Bayesian reasoning approach for prioritization of failures in FMEA. IEEE Trans Reliab 57(3):517-528

59. Yucesan M, Gul M (2019) Failure prioritization and control using the neutrosophic best and worst method. Gran Comput p 1-15.

60. Yucesan M, Gul M, Guneri AF (2021) A Bayesian network-based approach for failure analysis in weapon industry. J Therm Eng $7(2): 222-229$

61. Zadeh LA (1965) Fuzzy sets. Inform Control 8(3):338-353

62. Zarei E, Azadeh A, Khakzad N, Aliabadi MM, Mohammadfam I (2017) Dynamic safety assessment of natural gas stations using Bayesian network. J Hazard Mater 321:830-840

63. Zarei E, Khakzad N, Cozzani V, Reniers G (2019) Safety analysis of process systems using Fuzzy Bayesian Network (FBN). J Loss Prev Process Ind 57:7-16

64. Zhou Q, Thai VV (2016) Fuzzy and grey theories in failure mode and effect analysis for tanker equipment failure prediction. Saf Sci 83:74-79

65. Huang J, Li ZS, Liu HC (2017) New approach for failure mode and effect analysis using linguistic distribution assessments and TODIM method. Reliab Eng Syst Saf 167:302-309

66. Catelani M, Ciani, L, Venzi M (2018) Failure modes, mechanisms and effect analysis on temperature redundant sensor stage. Reliab Eng Syst Saf 180:425-433

67. Du Y, Lu X, Su X, Hu Y, Deng Y (2016) New failure mode and effects analysis: an evidential downscaling method. Qual Reliab Eng Int 32(2):737-746
68. Safari H, Faraji Z, Majidian S (2016) Identifying and evaluatinf enterprise architecture risks using FMEA and fuzzy VIKOR. J Intell Manuf 27(2):475-486

69. Lo HW, Liou JJ, Huang CN, Chuang YC (219) A novel failure mode and efect analysis model for machine tool risk analysis. Reliab Eng Syst Saf 183:173-183

70. Seiti H, Fathi M, Hafezalkotob A, Herrera-Viedma E, Hameed IA (2020) Developing the modified R-numbers for risk-based fuzzy information fusion and its application to failure modes, effects, and system resilience analysis (FMESRA). ISA Trans

71. Zhao H, You JX, Liu HC (2017) Failure mode and effect analysis using MULTIMOORA method with continuous weighted entropy under interval-valued intuitionistic fuzzy environment. Soft Comput 21(18):5355-5367

72. Kutlu AC, Ekmekcioglu M (2012) Fuzzy failure modes and effects analysis by using fuzzy TOPSIS-based fuzzy AHP. Expert Syst Appl 39(1):61-67

73. Zhang H, Dong Y, Xiao J, Chiclana F, Herrera-Viedma E (2020) Personalized individual semantics-based approach for linguistic failure modes and effects analysis with incomplete preference information. IISE Trans 52(11):1275-1296

Publisher's Note Springer Nature remains neutral with regard to jurisdictional claims in published maps and institutional affiliations. 